\title{
Thinking Internationally to Preserve Our Libraries ${ }^{1}$
}

\section{Brian L. Hawkins}

Brian L. Hawkins is senior vice president for academic planning and administrative affairs at Brown University. Address: Box 1885, Providence, RI 02912. Fax: (401) 863-7247.

A $\mathrm{s}$ the beginning of the 21 st century approaches, the very survival of our libraries is seriously threatened. While the electronic superhighway promises vast amounts of information available in an almost ubiquitous fashion, economic and technological forces are narrowing our citizens' access to information. School libraries are closing all over the United States, public libraries are cutting hours, and research libraries are canceling subscriptions to journals and library materials at an alarming rate.

Great as the economic threats to libraries are, however, perhaps the greater threat is the perception that technology will solve these problems, and that all someone has to do is search the World Wide Web for any information one needs. A vast amount of "information" is indeed available on the Web today, but it is not a coherent collection of information. In addition, the amount of scholarly, intellectual, and aesthetic information is a very small percentage of this total, and access to the Web is anything but egalitarian. These are a few of the concerns that must be communicated clearly to our college presidents and provosts if higher education is to deal effectively with these problems.

Great as the economic threats to libraries are, however, perhaps the greater threat is the perception that technology will solve these problems, and that all someone has to do is search the World Wide Web for any information one needs.

It is not surprising that people have come to believe that the digital library is already well on its way toward completion. We see television commercials suggesting that a student in Italy completed a doctoral dissertation by using digital resources via the library at the University of Indiana. What people fail to realize is that these important experiments are enormously costly, not systematic, and not sustainable without significant philanthropic and corporate support. Digitization of library materials is not happening en masse, nor is it likely to with each institution continuing to act independently. Contrary to apparent popular opin- ion, we are not moving switfly toward making library materials available electronically, and our current efforts are best characterized as experimental, episodic, and uncoordinated. In the meantime, we are rapidly losing financial capacity to support traditional library collections.

The reasons that libraries cannot be sus-
tained in their traditional form are es-
sentially economic in nature. The costs
of library acquisitions are far outstrip-
ping the growth in library budgets.

The reasons that libraries cannot be sustained in their traditional form are essentially economic in nature. The costs of library acquisitions are far outstripping the growth in library budgets. Acquisition costs, especially for periodicals, have increased over 12 percent annually since 1980 . Analyses have shown that while library budgets have grown over 8 percent annually during that time period, the result has been the loss of more than 40 percent of library power in the last 15 years. If these trends continue, by the end of the first quarter of the next century, libraries will have less than 5 percent of what was available less than 50 years previously to collect information in what will be known as the "age of information." Libraries are cutting subscriptions to journals and collecting less and less information each year, and there is no reason to believe that this downward spiral will cease any time soon. Other analyses-detailed elsewhere-show that to some extent other costs associated with libraries are similarly unsustainable-specifically the staffing requirements and the space costs in support of a collection. What is needed is a new paradigm, using technology and traditional library resources to turn this tide and to preserve library resources for the future.

Academic leaders, librarians, and technologists all seem to be waiting for the information revolution to arrive, apparently believing it is just around the corner because they keep hearing about it on television and reading about it in the press. We will not see this wonderful future, however, unless we focus on how to create it. If we do not begin immediately, our libraries, our educational institutions, and indeed the very intellectual fiber of our broader society could be in jeopardy.

Libraries clearly will not make the transition to the 21 st century using the current model. We must develop a 
new paradigm that meets the economic parameters of our institutions, yet still supports the traditional values of libraries and scholarship. While the economic problems are significant, we should not focus on this dilemma solely as a financial problem. The problem of long-term access to information, and the extent to which the scholarly record is being lost, should worry anyone concerned about the future of the university. Traditionally, libraries collect only about 6 percent of all information that is published. Without intervention, even this amount of preservation is in serious jeopardy.

Libraries clearly will not make the tran-
sition to the 21 st century using the cur-
rent model. We must develop a new
paradigm that meets the economic pa-
rameters of our institutions, yet still sup-
ports the traditional values of libraries
and scholarship.

It is clear that the current unit of analysis-the campus library-cannot survive in the existing environment. The leveraging of our library resources is clearly called for, with the best solution being at the largest system-level possible-an international group of cooperating libraries. While associations of campuses, consortia, and other groupings will alleviate the problem, the best solution is found when no system or national boundaries are limiting factors, but where information is maximally available. This principle is already shown to be operating in one of the few present examples of information that is available across virtually all existing boundaries:

For the sake of science, the knowledge base of molecular biology should be a public, international electronic library, supported by all for the benefit of all. No one organization or nation should control this type of information for public gain. Another reason for public ownership, especially of scientific knowledge, is that database and knowledge management is of such magnitude that individuals and their organizations cannot be expected to bear this burden as they have in the past. ${ }^{2}$

This illustrates the intellectual as well as economic advantages of a broader system. While there may be a sense of nostalgia for the self-contained library on campus, it is a luxury that is no longer affordable economically or intellectually if our libraries and educational systems are to survive.
Part of what keeps us focused on the smaller unit-ofanalysis of the campus is the tendency of our institutions to use the size of the campus library as a competitive factor, falling into the trap of "bigger is better." As long as we continue to rank libraries on the basis of the total number of holdings, we reinforce the suboptimization of information resources. It is only when access to information is ubiquitous that we can gain the economies of scale and the universal intellectual opportunities that are necessary. "Bigger is better" is not particularly meaningful in an electronic age, and is also an entirely relative statement when the unitof-analysis is that of a given institution or set of institutions. We can no longer afford this competitive stance; it is not only not cost-effective, but it is ultimately destructive as well.

The library of the future will be less a place where information is kept than a portal through which students and faculty will access the vast information resources of the world. This new library needs to bring together scholars and information resources without necessarily bringing either one to a physical building with a card catalog and books. The scholar may be at home, or in her laboratory, or in her classroom and the information may be in Kyoto, or Bologna, or on the surface of the moon. The library of the future will have the daunting task of helping scholars discover what relevant information exists-anywhere in the world, and in a variety of formats and media. The library of the future will be about access and knowledge management, not about ownership. The hurdles that will be faced in creating this new electronic environment are likely to come from our unwillingness to break with our competitive tendencies, our parochialism in glorifying the past, and our unwillingness to accept the inevitability of change. Almost 150 years ago, Thoreau suggested that "books are the treasured wealth of the world-the fit inheritance of generations and nations." ${ }^{3}$ It is yet to be determined whether our society is committed to making this inheritance a reality in the age of information.

C B Brian L. Hawkins, 1997. This article may be reprinted only with the permission of the author.

\section{NOTES}

${ }^{1}$ This article has been extracted from Brian L. Hawkins, "The Unsustainability of the Traditional Library and the Threat to Higher Education" (paper presented at the Stanford Forum on Higher Education Futures, Aspen, Colo., October 18, 1996).

${ }^{2}$ Nina W. Matheson, "Strategic Management: Knowledge as a National Resource" (paper presented at the Medical Librarians Association Annual Meeting, New Orleans, May 1988).

${ }^{3}$ Henry David Thoreau, Walden (Salt Lake City: Gibbs M. Smith 1981), 93. 